\title{
Educação Especial e Formação de Professores: contrapontos entre os contextos brasileiro e italiano
}

\author{
Special Education and Teacher's Formation: \\ counterpoints between the brazilian and italian contexts
}

\begin{abstract}
Resumo:
O estudo objetiva refletir acerca da formação continuada de professores para a inclusão escolar de alunos com deficiência nos contextos brasileiro e italiano. Com base em uma abordagem qualitativa, elegemos como movimentos metodológicos prioritários a revisão de literatura e análise de produções e documentos normativos relativos aos dois contextos. Assim, realizou-se um diálogo entre as diretrizes e perspectivas políticas e a constituição da escola e do professor. O texto divide-se em três partes analíticas, compreendendo que a formação continuada de professores, em ambos os contextos, garante: (1) sustentar uma formação pedagógica de qualidade; (2) constituir uma leitura flexível sobre a inclusão; (3) (re)significar as posturas da escola e do professor a partir de ambos os contextos. Assim, tem-se a possibilidade de não só oferecer acesso à escola, mas sustentar a aprendizagem, o pertencer e a efetividade de uma formação continuada de professores.

Palavras-chave: Formação de professores. Inclusão. Educação Especial.
\end{abstract}

\section{Abstract:}

The study aims to reflect on the continued formation of teachers for scholar inclusion of students with disabilities in the Brazilian and Italian contexts. Based on a qualitative approach, we choose as priority methodological movements, literature review and analysis of productions and normative documents relatives to the two contexts. Thus, there was a dialogue between guidelines and political perspectives and the constitution of the school and the teacher. The text is divided into three analytical parts, including the continued formation of teachers in both contexts, guarantees: (1) support a pedagogical formation of quality; (2) provide a flexible reading of the inclusion; (3) (re)define scholar's and teacher's attitudes from both contexts. Thus, there is the possibility of not only providing access to school but also support learning, belonging and the effectiveness of a continued formation of teachers.

Keywords: Teacher's formation. Inclusion. Special education.

SILVA, Mayara Costa da; MONTE, Bárbara Terra do. Educação Especial e Formação de Professores: contrapontos entre os contextos brasileiro e italiano. Informática na Educação: teoria e prática, Porto Alegre, v. 18, n. 2, p. 53-64, jul./ dez. 2015.
Mayara Costa da Silva

Bárbara Terra do Monte

\section{Introdução}

A defesa de uma educação de qualidade e de uma escola para todos tem sido foco da discussão acerca da Educação Especial na perspectiva da educação inclusiva nos últimos anos. A busca constante por respostas às questões cotidianas nos leva a refletir acerca da heterogeneidade presente em sala de aula, bem como sobre estratégias de ensino que sejam potentes e levem em consideração as singularidades presentes no processo de aprender de cada um. Nesse sentido, tal busca nos faz repensar ainda na qualificação dos professores, principalmente levando em consideração os processos de formação continuada. 
Dessa forma, no presente trabalho tem-se por objetivo desenvolver uma reflexão acerca da formação do professor especializado em Educação Especial tomando, para tanto, os modelos brasileiro e italiano como contextos de pesquisa. Nesse sentido, busca-se estabelecer um contraponto entre a formação do professor de apoio (Itália) e o professor de sala de recursos (Brasil), compreendendo a formação como um processo que proporciona a competência desses profissionais.

Destacamos, ainda com relação à formação de professores, a importância de refletirmos acerca de processos formativos que levem em consideração os contextos onde se inserem. Afirmamos, assim, que precisamos pensar em "[...] processos formativos que valorizam a relação teoria-prática, a reflexão crítica sobre os avanços e retrocessos da ação educativa e o contexto da sala de aula onde o ato de ensinar e aprender se realiza [...]" (JESUS; VIEIRA, 2011, p. 145).

Para tanto, recorremos ao diálogo entre os dois diferentes contextos educacionais anunciados. Nosso estudo se integra a uma perspectiva de pesquisa qualitativa, enfatizando o levantamento bibliográfico e a análise documental como movimentos metodológicos. Consideramos a relevância da revisão bibliográfica na medida em que ela nos apresenta movimentos e contornos para compreender o que vem sendo produzido acerca da temática discutida. Do mesmo modo, priorizamos a análise documental dos documentos normativos da área que congregam importantes discussões relativas à inclusão de alunos com deficiência.

A metodologia de pesquisa utilizada possibilita o desenvolvimento de uma análise aprofundada das questões levantadas no presente estudo: Quais as relações existentes entre a formação oferecida ao Insegnante di sostegno (professor de apoio) e ao professor do Atendimento Educacional Especializado? Quais têm sido os direcionamentos priorizados em cada um dos contextos com vistas à inclusão escolar de alunos com deficiência?

Baseando-nos nesses questionamentos, podemos vislumbrar significativos avanços ocorridos na área da Educação Especial, o que amplia a necessidade de discussões e reflexões acerca da temática formação de professores. Tais reflexões encontram-se em consonância com Caiado, Jesus e Baptista (2011) quando afirmam que o debate se constitui ainda como emergencial na área.

Além dos referidos avanços, destacamos o contínuo aumento das matrículas de alunos com deficiência em escolas regulares. Conforme os dados do Censo Escolar do Brasil relativos ao ano de 2013, pontuados pelo Ministério da Educação (MEC) ${ }^{1}$ (2014), há aproximadamente $86,22 \%$ de crianças com deficiência matriculadas em escolas regulares nos últimos cinco anos.

No âmbito do contexto italiano, o mesmo movimento pode ser percebido. Di Pasquale e Maselli (2014, p. 711) apontam que "[...] de um total de matrículas de 7.300.000 alunos [no ensino regular], 215.590 foram identificados como alunos com deficiência em 2012". Nesse sentido, as autoras ressaltam que, ao compararmos os dados referentes ao número de matrículas realizadas nos anos de 2001 e de 2012, é significativo o aumento ocorrido no ano mais recente, uma vez que em 2001, perfaziam um total de 126.994 matrículas de alunos com deficiência matriculados no ensino regular.

Destacamos a importância de lançarmos nosso olhar para esses dados, levando em con-

${ }^{1}$ Disponível em: <http://portal.mec.gov.br>.Acesso em: 11 dez. 2014. 
sideração que eles nos oferecem pistas para refletirmos sobre o processo de inclusão escolar. Consequentemente, esses mesmos dados implicam a necessidade de discussão acerca de uma formação docente consistente para a implementação de tal processo.

Diante dessas premissas, consideramos como imperativa a necessidade de debruçarmo-nos sobre a temática que envolve a formação de professores relacionada à Educação Especial, dedicando-nos entre os diálogos que compõem diferentes contextos, desvelando a inclusão como processo promissor e complexo.

\section{Formação de Professores e Edu- cação Especial: contexto brasileiro}

Tomando como referência as salas de aula e o exercício docente, podemos afirmar que as exigências presentes no contexto da escola crescem diariamente, principalmente na educação básica. Assim, apontamos como necessárias novas/outras formas de ser e de fazer escola (MEIRIEU, 1998).

Como já foi anunciado de maneira prévia, o presente texto visa a explorar a discussão que envolve a formação continuada de professores para atuar diretamente com o alunado público alvo da Educação Especial. O foco é a formação do professor de Atendimento Educacional Especializado. Com vistas a fomentar a discussão que envolve os processos formativos e a Educação Especial, consideramos necessário proceder a uma breve retomada dos documentos orientadores oficiais que envolvem o tema. Assim, com o intuito de situar o leitor, faremos uma breve reconstituição histórica desses marcos legais e políticos.

Podemos afirmar a importância da década compreendida entre os anos 2000 e 2010, ten- do em vista os intensos movimentos da área. No ano de 2003, foi aprovado o Programa Educação Inclusiva: direito à diversidade, uma iniciativa ministerial que tem como principal objetivo "[...] a formação de gestores e educadores para efetivar a transformação dos sistemas educacionais em sistemas educacionais inclusivos" (BRASIL, 2006b, p. 1). Nesse sentido, visa a oferecer uma educação de qualidade a alunos com deficiência.

No ano de 2008, foi firmada a Política Nacional de Educação Especial na Perspectiva da Educação Inclusiva. Conforme descrito por Griboski (2008, p. 57), "para além de um documento orientador, a Política passa a se constituir num marco na organização do sistema educacional inclusivo [...]". O documento enfatiza a importância e a necessidade de garantir uma "[...] formação de professores para o atendimento educacional especializado e demais profissionais da Educação para a inclusão escolar [...]" (BRASIL, 2008, p. 8). Ressalta ainda que para atuar na Educação Especial, o professor precisa poder contar, em sua formação inicial e continuada, com conhecimentos gerais e específicos que o capacitem para o exercício da docência. Torna-se possível perceber que:

A temática sobre a formação de professores tem sido recorrente nas diversas ações governamentais, como forma de aprimorar a qualidade de ensino da Educação Básica. Mas longe de ser um assunto simples, essa área de conhecimento tem se mostrado extremamente complexa, com nuances e dilemas que provocam o debate na comunidade acadêmica. Posições dualistas ou dicotomias sobre o conteúdo e as competências de formação levam necessariamente a um reducionismo que ignora a complexidade sistêmica da questão (PASSERINO, 2011, p. 77). 
A Resolução CNE/CEB no 04/2009 institui diretrizes operacionais para o Atendimento Educacional Especializado (AEE) na educação básica. O referido documento determina que os sistemas de ensino devem matricular os alunos com deficiência nas classes comuns do ensino regular, bem como no Atendimento Educacional Especializado, que tem como função complementar ou suplementar a escolarização oferecida na sala de aula regular, oferecendo "[...] serviços, recursos de acessibilidade e estratégias que eliminem as barreiras para sua plena participação na sociedade e desenvolvimento de sua aprendizagem" (BRASIL, 2009, p. 1). Além de ser de caráter complementar ou suplementar ao ensino regular, deve ser oferecido preferencialmente em Salas de Recursos Multifuncionais ${ }^{2}$ no turno inverso ao da escolarização.

Segundo a Resolução CNE/CEB nº 04/2009, constituem-se como algumas das principais atribuições do professor responsável pelo Atendimento Educacional Especializado:

[...] identificar, elaborar, produzir e organizar serviços, recursos pedagógicos, de acessibilidade e estratégias considerando as necessidades específicas dos alunos público-alvo da Educação Especial; elaborar e executar plano de Atendimento Educacional Especializado, avaliando a funcionalidade e a aplicabilidade dos recursos pedagógicos e de acessibilidade. [...] estabelecer articulação com os professores da sala de aula comum, visando à disponibilização dos serviços, dos recursos pedagógicos e de acessibilidade e das estra-

\footnotetext{
2 Salas de Recursos Multifuncionais são espaços da escola onde se realiza o atendimento educacional especializado para alunos com deficiência, de acordo com o documento orientador desenvolvido pelo MEC, com vistas a auxiliar na organização do atendimento educacional especializado. As intervenções realizadas no âmbito das Salas de Recursos são desenvolvidas "[...] por meio do desenvolvimento de estratégias de aprendizagem centradas em um novo fazer pedagógico que favoreça a construção de conhecimentos pelos alunos [...]" (BRASIL, 2006b, p. 13).
}

tégias que promovem a participação dos alunos nas atividades escolares (BRASIL, 2009, p. 3).

Diante desse quadro, temos apostado na percepção de que a profissão que envolve a docência necessita de processos contínuos de aprendizagens a partir dos quais se busca constante atualização no que tange aos desafios que permeiam os sistemas de ensino, os diferentes espaços escolares, assim como as salas de aula. Nesse sentido,

[...] a formação de professores é um processo de ensino e aprendizagem que contempla a complexidade de qualquer processo educativo com suas numerosas variáveis, mas acrescenta ainda os dilemas do 'ser-professor-aluno', em uma dinâmica de formação que busca trabalhar dialógica e dialeticamente com o binômio teoria-prática. Portanto, todo processo de formação, seja esse inicial ou continuado, requer explicitar a relação teoria-prática na proposta pedagógica do currículo. (PASSERINO, 2011, p. 77)

Nos diversos espaços, nos encontros com o outro, nas construções de estratégias pedagógicas, as variáveis entre o ser e o fazer encenam uma formação. A encenação ${ }^{3}$ de um saber/fazer sinaliza a emergência de uma for-

\footnotetext{
${ }^{3} \mathrm{O}$ conceito de encenação envolve o apresentar, que se constitui num sistema completo, numa estrutura em que cada elemento se integra ao conjunto. Ou, conforme Copeau (1974), é o desenho de uma ação dramática, composta por um conjunto de movimentos, gestos e atitudes, das vozes e dos silêncios, que na sua totalidade emana um pensamento único que o concebe, rege e harmoniza. Quem encena inventa e faz reinar entre todos um vínculo secreto e invisível, na reciprocidade das relações. E ao questionar-se de uma ação dramática, reporta-se a Gusfield (1989), que afirma que o drama implica uma ação, e não um movimento, e que a ação é dramática por incluir o conflito, o propósito, a reflexão e a escolha. Burke (1969) delimita a ação ao formular o quinteto dramático, expondo que para haver um ato, deve haver um agente, e que paralelamente, deve haver uma cena na qual o agente age. Para agir, esse agente deve empregar alguns meios ou instrumentos, nos quais envolve um propósito. Nesse sentido, referimo-nos à escola, à educação e seus atores (aluno e professor), que engendram a todo o momento uma transformação.
} 
mação que suporte um ensino-aprendizado de e para todos. Um formar que seja fortalecido na teoria e na prática como elos existentes e enraizados de uma perspectiva sócio-histórica, na qual se busca a significação para a vida e para a nossa própria história, seja essa significação factual ou (re)inventada nas diferentes instâncias sociais. Um formar que se compõe como um discurso de reflexão e de descobertas alicerçadas nas perspectivas intrapessoal e interpessoal, ancorados na interação social e na linguagem, conceitos pautados na perspectiva de Vygotsky (2007).

Bridi (2011, p. 193) afirma que "a oferta do atendimento educacional especializado e a implementação das salas de recursos multifuncionais em escolas do ensino comum têm sido acompanhadas por uma crescente demanda na formação de professores". Nesse sentido, compreendemos a necessidade de refletir acerca do trabalho que envolve o profissional do atendimento educacional especializado, buscando significar os principais aspectos que envolvem um formar repleto de peculiaridades e repercussões promissoras para o processo de incluir.

Como foi destacado anteriormente, entre as demais contribuições trazidas pela Política Educacional de 2008, sobressai a garantia de formação de professores para o Atendimento Educacional Especializado, assim como aos demais profissionais da educação para a inclusão escolar.

Cabe ressaltar que no ano de 2006, especificamente a partir da Resolução CNE/CP no 01/2006 - que estabelece as Diretrizes Curriculares Nacionais para o Curso de Graduação em Pedagogia -, foi extinta a graduação em pedagogia que formava professores habilitados para determinadas áreas, como a Educação Especial. Bridi (2012, p. 53) refere que depois disso, "[...] a tendência é que se acentue cada vez mais uma política de formação continuada e de ampliação dos cursos de pós-graduação".

No contexto brasileiro, tem sido priorizada a formação continuada do professor especialista em Educação Especial. A partir dessa percepção, têm se multiplicado cada vez mais os tipos e formatos de cursos de especialização que envolvem a temática da educação especial e da inclusão escolar. O Curso de Pós-Graduação Lato Sensu em nível de especialização habilita o professor para atuar no Atendimento Educacional Especializado, no âmbito das Salas de Recursos Multifuncionais.

De acordo com a Resolução CNE/CEB no 02 de 2001, são considerados professores especializados em Educação Especial aqueles que:

[...] desenvolveram competências para identificar as necessidades educacionais especiais para definir, implementar, liderar e apoiar a implementação de estratégias de flexibilização, adaptação curricular, procedimentos didáticos pedagógicos e práticas alternativas, adequados ao atendimentos das mesmas, bem como trabalhar em equipe, assistindo o professor de classe comum nas práticas que são necessárias para promover a inclusão dos alunos com necessidades educacionais especiais (BRASIL, 2001, p. 5).

Em suma, destacamos a importância de que a formação do professor especializado em Educação Especial invista, antes de qualquer coisa, em um viés que valorize os aspectos pedagógicos. Bueno (1999) apresenta-nos algumas necessidades que conjugam a formação de professores para a Educação Especial. Destaca que o professor deve ter acesso a uma formação teórica sólida que envolva os diversos processos e procedimentos pedagógicos, abrangendo tanto o saber como o saber fazer. Nesse sentido, afirmamos a necessidade da valorização de uma formação ampla, que 
favoreça, prioritariamente, a formação de um professor.

\section{Formação de Professores e Edu- cação Especial: contexto italiano}

O professor de apoio é considerado um professor cujos conhecimentos devem ser, prioritariamente, pautados no saber pedagógico. Essa é uma concepção bastante difundida na realidade Italiana.

As mudanças no contexto italiano com relação à inclusão escolar tiveram seu início em meados de 1970 (BAPTISTA, 2009). Em 1977, foi aprovada na Itália uma lei - Lei no 517, de 1977 - que extinguiu as classes especiais, direcionando todos os alunos considerados público alvo da Educação Especial para as escolas regulares. Dessa forma, a partir da aprovação da referida Lei que trata da Integrazione Scolastica, todos os alunos passam a ser incluídos no sistema regular de ensino. Além disso, Greguol, Gobbi \& Carraro (2013) afirmam que

[...] a lei trouxe algumas garantias relevantes, tais como o estabelecimento do numero máximo de 20 alunos nas classes em que houvesse um aluno com deficiência e a presença de um professor para auxilio, que a partir deste momento não seria mais chamado de professor especializado, mas sim de professor de apoio ou insegnante di sostegno (GREGUOL; GOBBI; CARRARO, 2013, p. 316).

O professor de apoio ou insegnante di sostegno forma-se em cursos de especialização que se caracterizam - cabe ressaltar - pela abordagem predominantemente generalista, aquela que forma o professor especializado em Educação Especial apresentando conhecimen- tos amplos, abordando as diferentes subáreas dessa modalidade de educação. Nesse sentido, tais cursos se configuram em uma formação pautada no conhecimento pedagógico em detrimento de uma formação especialística, na qual se parte de uma determinada deficiência.

Baptista (2009) refere que o trabalho do professor de apoio envolve

[...] a intervenção direta com o aluno; a colaboração dirigida aos colegas docentes, fazendo com que sejam reduzidos os momentos de intervenção individual e potencializadas as ações dos demais docentes por meio de instrumentos e técnicas compartilhadas; além disso, são importantes as atividades de documentação das experiências e de reflexão sobre os percursos (BAPTISTA, 2009, p. 21).

A partir das contribuições de Baptista (2009), ressaltamos a devida importância que deve ser dada ao diálogo e às parcerias constituídas entre os professores envolvidos na educação do aluno com deficiência - o professor da sala de aula comum e o professor de apoio. No contexto italiano, este é um aspecto prioritário quando se fala sobre a inclusão escolar: a percepção de que o trabalho docente de ambos os professores deve ocorrer de maneira articulada. Essa é uma questão emergente também no contexto brasileiro.

Ao buscarmos informações acerca do currículo que compõe a formação do professor de apoio na Itália, chama atenção a obrigatoriedade de estágios específicos, um aspecto que não se observa nos cursos de especialização no Brasil e que tem sido apontado como de grande importância. Silva (2012), a partir de uma pesquisa que envolveu alunas de um curso de especialização e a temática educação especial e processos inclusivos, percebeu que a necessidade de vivência/prática foi apontada como emergente pelas discentes. Assim, reitera a 
importância de relacionar os estudos teóricos desenvolvidos ao longo do curso com a prática pedagógica.

Greguol, Gobbi e Carraro (2013) apontam a promulgação do Decreto no 249 de 2010 na Itália - que trata das especificidades para a formação docente naquele país - como um fato relevante para o processo inclusivo. Segundo os referidos autores, esse decreto reforça:

A importância e o papel deste profissional [professor de apoio] para a inclusão bem sucedida de alunos com necessidades educacionais especiais, e coloca novas exigências mínimas para a sua formação. [...] os egressos dos cursos de formação docente que desejem obter a especialização em ensino de apoio devem cursar ao menos 60 créditos formativos (1500 horas), dos quais 12 (300 horas) são dedicados aos estágios específicos na escola [...] (GREGUOL; GOBBI; CARRARO, 2013, p. 318).

No contexto italiano também é dado destaque para a documentação pedagógica como instrumento de registro e de acompanhamento da trajetória do aluno. Além disso, tal documentação constitui-se em um recurso com potencial formativo, na medida em que os documentos são compartilhados entre os professores. Logo, atuando para além de uma simples ponte de comunicação, proporciona uma rica oportunidade para trocas e formação em serviço. Monteiro (2003) ressalta que a documentação passa a ser vista como

[...] ferramenta indispensável para a realização da avaliação do trabalho vivido por todos os seus atores, à medida que todos os passos são registrados. O material daí produzido é utilizado na comunicação entre professor e aluno, professor e família, professor e comunidade, professor e professores; e pela Uni- versidade que oferece apoio técnico. Nesse processo, a escola tem uma responsabilidade fundamental, mas não exclusiva, porque são envolvidas instituições variadas: a família, a administração municipal, a universidade, o centro de documentação (MONTEIRO, 2003, p. 40).

A partir das pontuações realizadas com relação à formação do professor especializado em educação especial na Itália (insegnante di sostegno), podemos perceber algumas questões relevantes, como a ênfase dada à importância do diálogo não só entre professores, mas também entre os demais membros da comunidade escolar, inclusive a família. Afirmam Di Pasquale e Maselli:

A inclusão de qualidade está ligada, portanto, ao crescimento de uma qualificação de competências tanto em termos de estrutura quanto do exercício da responsabilidade pessoal: não é um aspecto particular, mas um desafio coletivo que põe em questão todo o sistema escolar (DI PASQUALE; MASELLI, 2014, p. 714).

Esse destaque conferido à responsabilidade coletiva constitui-se como uma pista de suma importância nesse contexto e que diz muito a respeito do investimento que tem sido feito em prol da inclusão escolar. Tal investimento resulta em efeitos importantes, por exemplo, a compreensão de que o trabalho do professor de apoio não precisa ser realizado em um espaço diferente da sala de aula, mas que deve ocorrer de maneira articulada com aquele espaço. Essa percepção é importante quando se discute a inclusão escolar. 


\section{As Nuances das Educações En- trelaçadas Pela Inclusão}

Entre pontos e contrapontos, os dois contextos pesquisados apresentam aspectos relevantes envolvendo a área da Educação Especial. Os caminhos que Brasil e Itália escolheram são diferentes, mas se interseccionam quando o princípio é uma escolarização de qualidade para todos, sem distinção enquanto capacidade e possibilidade do ensinar e do aprender, do ser e do fazer (MEIRIEU, 1998).

Ambos os contextos iniciaram delineamentos nas legislações em torno dos anos 70. 0 Brasil trouxe em primeira instância, com a LDB n० 4.024 de 20 de dezembro de 1961, uma perspectiva integradora na qual articulava questões dos serviços especializados e uma educação mais igualitária. Mesmo sendo pouco aceita pela sociedade, principalmente quando nos reportamos ao meio educacional, essa Lei foi o pontapé inicial para um ensinar preocupado com os sujeitos à margem de preconceitos e discriminações, cercados de desconhecimentos e práticas educativas limitadoras.

Na Itália, a década de 1970 trouxe várias transformações na escolarização de sujeitos com necessidades específicas, alargando possibilidades de uma educação promissora para todos. O contexto italiano inovou ao extinguir as escolas especiais e as classes diferenciadas. Tal atitude difere do contexto brasileiro, que embora possua leis e políticas educacionais voltadas para a inclusão, ainda valoriza espaços educacionais específicos que delimitam as possibilidades e capacidades desses sujeitos, em sua maioria rotulados por diagnósticos e manuais clínicos.

Ao centralizar o foco na inclusão, não podemos deixar de fazer uma referência ao termo anterior integração, cujos significados são dis- tintos entre os dois países no emprego de tal expressão. No Brasil, usamos integração para definir uma situação que agrega o indivíduo ao espaço já organizado e com regras constituídas, em que ele deverá se adaptar a essa nova realidade para participar de um meio cristalizado e deficitário de leis que garantam seus direitos. Em contraponto, na Itália o termo integração "[...] guarda uma forte identidade com a grande reforma realizada no país por meio da integrazzione scolastica, o que já indicava uma prática educacional nos moldes do que é proposto pela perspectiva inclusiva a partir dos anos de 1980" (RAHME, 2013, p. 106).

Por esse enfoque, o princípio da Formação continuada, ponto central deste estudo, também encena diferentes paradigmas, mas que se baseiam nas mesmas premissas educacionais - dar sustento ao ensino e ao aprendizado de crianças que nos interrogam nos tradicionais processos de fazer e ser professor. Ambos os países apostam no lugar fulcral do professor para que se estabeleçam e se produzam efeitos nos campos subjetivo, social etc. Trata-se de uma presença forte, propositiva. Um Ato! Ato capaz de mediar significados, iniciativas e experiências sociais e culturais.

No entanto, como vimos na primeira sessão deste estudo, para atuar no Atendimento Educacional Especializado no Brasil, o professor precisa ter em seu currículo, no mínimo, um curso de especialização na área da Educação Especial. De acordo com a Política Nacional de Educação Especial na Perspectiva da Educação Inclusiva (PNEE-EI) de 2008, o profissional da educação deverá ter "[...] como base da sua formação, inicial e continuada, conhecimentos gerais para o exercício da docência e conhecimento específicos na área" (BRASIL, 2008, p. 11).

O profissional do AEE dispõe de um espaço e de recursos educacionais para enriquecer 
o desenvolvimento cultural, social e cognitivo dos alunos com deficiência e/ou transtornos. Em seu atendimento, é necessário que esse professor " $[. .$.$] atue de forma articulada com o$ ensino comum [...]" (DORZIAT, 2011, p. 154). Nos últimos anos, sua formação tem sido tratada com mais atenção por parte das iniciativas governamentais (DORZIAT, 2011), por conta do grande aumento no número de matrículas no ensino regular de alunos com deficiência, conforme foi apontado anteriormente.

No contexto Italiano, não existe a figura do professor do AEE, mas sim, o professor de apoio, denominado nesse contexto Insegnante di sostegno. Tal profissional atua junto ao professor regente da sala de aula de maneira articulada, contribuindo não somente para a integração do aluno com deficiência, mas no planejamento pedagógico, avaliações, organização do espaço da sala de aula. Logo, ele é responsável também pela parte curricular.

Percebemos as inúmeras articulações que cada contexto compõe quando abordamos os temas inclusão escolar e formação de professores, cercados de transformações políticas, sociais e educacionais, que envolvem não somente alunos considerados da Educação Especial, mas todos os sujeitos de uma sociedade crítica e consciente de seus direitos e deveres.

\section{Desvelando Considerações Ilimi- tadas de Conclusões}

A partir da leitura e análise dos dois contextos - Brasil e Itália - e tomando como base o processo que envolve a educação inclusiva, priorizando a formação do professor de educação especial, podemos perceber muitas diferenças, principalmente com relação à organização do sistema escolar, porém também podemos vislumbrar algumas aproximações que indicam pistas dos pontos de intersecção entre os dois contextos estudados.

Como já foi destacado anteriormente, a busca por uma educação de qualidade para todos é o primeiro ponto que aproxima os dois contextos. Além disso, observamos haver uma percepção compartilhada em ambos: a da importância de uma formação que prepare o professor para a docência de fato, priorizando os aspectos pedagógicos em detrimento de especificidades da deficiência.

Nesse sentido, concluímos o presente estudo reafirmando a importância de que a formação de professores relacionada à educação especial não enfatize as deficiências, mas sim, busque estabelecer uma reflexão junto aos docentes acerca do olhar para além das dificuldades do aluno, valorizando, antes de qualquer coisa, as potencialidades apresentadas por ele.

Finalizamos e reafirmamos a emergência da construção de políticas de formação continuada, com vistas a constituir uma escola realmente inclusiva. Um formar preocupado com o oferecimento de uma educação de qualidade para todos. Abonando destaque às palavras de Dorziat, que retoma a importância de buscarmos desconstruir as previsibilidades pensadas acerca "[...] do mesmo professor, do mesmo programa, do mesmo manual, do mesmo tempo, do mesmo ritmo, do mesmo espaço" (DORZIAT, 2011, p. 158).

Por fim, não existem receitas certas quando nos propomos a pensar a educação e a formação de professores. Afinal, é neste aspecto que reside a riqueza do constituir-se docente: na potência do questionamento, no desafio, na possibilidade de construir novos caminhos e delinear novas rotas, a partir das relações tecidas no cotidiano escolar. 


\section{Referências}

BAPTISTA, C.R. À italiana? Uma análise do percurso histórico da inclusão escolar. In: BAPTISTA, C.R.; JESUS, D. (Org.). Avanços em Políticas de Inclusão: o contexto da educação especial no Brasil e em outros países. Porto Alegre: Mediação, 2009. P. 11-27.

BRASIL. Ministério da Educação. Lei n. 4.024, de 20 de dezembro de 1961. Fixa as Diretrizes e Bases da Educação Nacional. Brasília, 1961. Disponível em: <http://wwwp.fc.unesp.br/ lizanata/LDB\%20 4024-61.pdf> Acesso em: 11/ dez/ 2014.

BRASIL. Ministério da Educação. Lei n. 9.394, de 20 de dezembro de 1996. Estabelece as diretrizes e bases da educação nacional. Brasília, 1996.

BRASIL. Ministério da Educação. Resolução CNE/CEB No 2, de 1 de setembro de 2001. Institui Diretrizes Nacionais para a Educação Especial na Educação Básica. Conselho Nacional de Educação. Câmara de Educação Básica. Diário Oficial da União, Brasília, 14 de setembro de 2001. Seção 1E, p. 39-40. Disponível em: <http://portal.mec.gov.br/cne/arquivos/pdf/CEB0201.pdf> Acesso em: 11/ dez/ 2014.

BRASIL. Ministério da Educação. Resolução CNE/CEB No 4, de 2 de outubro de 2009. Institui Diretrizes Operacionais para o Atendimento Educacional Especializado na Educação Básica, modalidade Educação Especial. Diário Oficial da União, Brasília, 5 de outubro de 2009. Seção 1, p. 17. Disponível em: <http://portal.mec.gov.br/dmdocuments/rceb004_09.pdf> Acesso em: 11/ dez/ 2014.

BRASIL. Ministério da Educação. Resolução CNE/CP No 1, de 15 de maio de 2006a. Institui Diretrizes Curriculares Nacionais para o Curso de Graduação em Pedagogia, licenciatura. Diário Oficial da União, Brasília, 16 de maio de 2006. Seção 1, p. 11. Disponível em: <http://portal.mec.gov.br/cne/ arquivos/pdf/rcp01_06.pdf> Acesso em: 11/ dez/ 2014.

BRASIL. Ministério da Educação. Secretária de Educação Especial. Política Nacional de Educação Especial na Perspectiva da Educação Inclusiva. Brasília: MEC/SEESP, 2008.

BRASIL. Ministério da Educação. Secretaria de Educação Especial. Programa Educação Inclusiva: direito à diversidade. Brasília, 2006b. Disponível em: <http://portal.mec.gov.br/seesp/arquivos/pdf/ orientador1.pdf> Acesso em: 11 set. 2012.

BRIDI, F.R.S. Formação continuada em educação especial: o atendimento educacional especializado. Poiésis, Tubarão, SC, n. 7, p. 187-199, Jan/Jun. 2011.

BRIDI, F.R.S. Formação Continuada em Educação Especial: o atendimento educacional especializado. IN: ROZEK, M.; VIEGAS, L.T. Educação Inclusiva: política, pesquisa e formação. Porto Alegre: EDI- 
PUCRS, 2012. p. 49-61.

BUENO, J.G.S. Crianças com Necessidades Educativas Especiais, Política Educacional e a Formação de Professores: generalistas ou especialistas? Revista Brasileira de Educação Especial, Piracicaba, n. 5, p. 7-25, 1999.

BURKE, K. A grammar of motives. Berkeley: University of California Press, 1969.

CAIADO, K.; JESUS, D.M.; BAPTISTA, C.R. (Org.). Professores e Educação Especial: formação em foco. Porto Alegre: Mediação, 2011. V. 1-2.

COPEAU, J. Registres I: Appels. Paris: Gallimard, 1974.

DORZIAT, A. A Formação de Professores e a Educação Inclusiva: desafios contemporâneos. In: CAIADO, K.; JESUS, D.M.; BAPTISTA, C.R. Professores e Educação Especial: formação em foco. Porto Alegre: Mediação/CDV/FACITEC, 2011. V. 2, p. 147-159.

GREGUOL, M.; GOBBI, E; CARRARO A. Formação de Professores Para a Educação Especial: uma discussão sobre os modelos Brasileiro e Italiano. Revista Brasileira de Educação Especial, Marília, v. 19, n. 3, p. 307-324, 2013.

GRIBOSKI, C.M. Inclusão. Revista Educação Especial, Brasília, v. 5, n. 1, p.57-58, jan./jun. 2008.

GUSFIELD, J.R. Kenneth Burke on symbols and society. Chigaco: University of Chigago Press, 1989.

JESUS, D.M. de; VIEIRA, A.B. Formação de Profissionais da Educação e Inclusão escolar: conexões possíveis. In: MAGALHÃES, R. de C.B.P.(Org.). Educação Inclusiva: escolarização, política e formação docente. Brasília: Líber Livro, 2011. P. 135-156.

MEIRIEU, P. Aprender... sim, mas como. 7. ed. Porto Alegre: Artes Médicas, 1998.

MONTEIRO, A.T.M. Educação Inclusiva: um olhar sobre o professor. 2003. Dissertação (Mestrado em Educação) - Faculdade de Educação, Universidade Federal de Minas Gerais, 2003, Belo Horizonte, BR-MG.

PASSERINO, L.M. Uma Experiência em Formação de Professores na Modalidade EAD. In: CAIADO, K.; JESUS, D.M.; BAPTISTA, C.R. (Org.). Professores e Educação Especial: formação em foco. Porto Alegre: Mediação/CDV/FACITEC, 2011. V. 1. 
RAHME, M.M.F. Inclusão e Internacionalização dos Direitos à Educação: as experiências brasileira, norte-americana e italiana. Educação e Pesquisa, São Paulo, v. 39, n. 1, p. 95-110, 2013.

SILVA, M.C. Percursos de Formação em Educação Especial: uma reflexão acerca da formação especializada. 2012. Trabalho de Conclusão de Curso - Curso de Pedagogia: Licenciatura, Faculdade de Educação, Universidade Federal do Rio Grande do Sul, 2012, Porto Alegre, BR-RS.

VYGOTSKY, L.S. A Formação Social da Mente: o desenvolvimento dos processos psicológicos superiores. 7. ed. São Paulo: Martins Fontes, 2007.

Submetido para avaliação em 13 de dezembro de 2014. Aprovado para publicação em 31 de março de 2015.

Mayara Costa da Silva - Universidade Federal do Rio Grande do Sul, Porto Alegre, BR-RS. E-mail: mayacsilva@gmail. com

Bárbara Terra do Monte - Universidade Federal do Rio Grande do Sul, Porto Alegre, BR-RS. E-mail: babi.m1298@ gmail.com 